\title{
The value of applying a melatonin antagonist (Luzindole) in improving the success rate of the bipedal rat scoliosis model
}

Shuo Yang ${ }^{1}$, Chaojun Zheng ${ }^{1}$, Jianyuan Jiang ${ }^{1}$, Feizhou Lu ${ }^{1,2}$, Xinlei Xia ${ }^{1}$, Wei Zhu' ${ }^{1}$ Xiang Jin ${ }^{1}$ and Xiaosheng Ma ${ }^{1 *}$

\begin{abstract}
Background: An ideal animal model has always been the key to research the pathogenesis and treatment of adolescent idiopathic scoliosis (AIS), while available methods have obvious disadvantages. The deficiency of melatonin has been proved relating to AIS. In this research, we intended to apply Luzindole, the melatonin antagonist, in bipedal rat model, for the block of combination of melatonin and its receptor, to inhibit the melatonin effect, and then to understand whether this method can effectively improve the scoliosis rate of bipedal rat model, and investigate the role of melatonin in scoliosis. To investigate the feasibility of improving the success rate of bipedal rat scoliosis model via intraperitoneal injection of melatonin antagonist (Luzindole).
\end{abstract}

Methods: A total of 60 3-weeks-old Sprague-Dawley rats were included in this study, and were divided into 3 groups ( $A, B$ and $C$ ). Each group included 20 rats. Osteotomy of the bilateral proximal humerus and proximal tailbone was performed in group A and group B; intraperitoneal injection of Luzindole $(0.2 \mathrm{mg} / \mathrm{kg})$ was performed in group A and group C. X-rays were taken before the surgery, 1 month after the surgery, 3 months after the surgery, and 6 months after the surgery, to calculate the Cobb's angle of the spine ( $>10^{\circ}$ was considered scoliosis). The weight of every rat was also measured at the same time. Rats were euthanized 6 months after surgery to determine the calmodulin level in thrombocytes.

Results: The rate of scoliosis in group A (14/20) was significantly higher than those in group B (6/20) and group C (0/20) $(P<0.05)$. The differences in the weights of the 3 groups were non-significant; as were differences in the calmodulin level in thrombocytes.

Conclusion: The application of the melatonin antagonist of Luzindole can improve the success rate of the bipedal rat scoliosis model. Meanwhile, this study indicates that a decreased melatonin level is not the primary cause of scoliosis, but that it may increase the likelihood and severity of scoliosis.

Keywords: Scoliosis, Melatonin antagonist, Bipedal rat model

\footnotetext{
* Correspondence: mxs893@sina.com

'Department of Orthopedics, Huashan Hospital, Fudan University, No.12,

Middle Wulumuqi Road, Shanghai 200040, China

Full list of author information is available at the end of the article
}

(c) The Author(s). 2017 Open Access This article is distributed under the terms of the Creative Commons Attribution 4.0 International License (http://creativecommons.org/licenses/by/4.0/, which permits unrestricted use, distribution, and reproduction in any medium, provided you give appropriate credit to the original author(s) and the source, provide a link to the Creative Commons license, and indicate if changes were made. The Creative Commons Public Domain Dedication waiver (http://creativecommons.org/publicdomain/zero/1.0/) applies to the data made available in this article, unless otherwise stated. 


\section{Background}

Adolescent idiopathic scoliosis (AIS) is a three-dimensional spinal deformity that occurs around the puberty, though the cause is currently unclear [1, 2]. However, related randomized controlled trial (RCT) studies in humans are unethical [3]. Therefore, an ideal animal model has always been the key to researching the pathogenesis and treatment of AIS.

The bipedal rat model was established by Goff in 1957. In Goff's study, osteotomy of the bilateral proximal humerus and proximal tailbone was performed to make bipedal rats, and scoliosis could develop due to continuous weight bearing. Its beneficial qualities, including ease of induction, low cost, and the similar anatomical construction of rats to human beings, led to the widespread use of the bipedal rat model in studies on AIS [4]. However, due to a low success rate, the establishment of the bipedal rat model requires additional factors to increase the success rate [3, 5-8].

In 1959, Thillard unintentionally discovered that after pineal body excision, chickens always develop scoliosis, which indicates that abnormality of the melatonin level has a certain correlation with scoliosis [9]. Recent studies have shown that AIS patients have a lower melatonin level compared to individuals of the same age group, which indicates that a lower melatonin level has an explicit correlation with AIS $[10,11]$. Therefore, a bipedal rat model with melatonin inhibition has been one of the major methods used to establish a scoliosis animal model. However, commonly used methods, such as pineal body excision [12, 13], continuous illumination [11, 14], and C57BL mice [7], still have some disadvantages, including their high cost, complicated preparation, and high mortality rate, among others etc. Some studies have even proved that a decreased melatonin level alone cannot effectively induce scoliosis [5], perhaps because the blood melatonin level has been partially inhibited, but the effect of melatonin has not been impacted.

Therefore, in this study, we administered Luzindole, a melatonin antagonist that blocks melatonin binding to its receptor, in the bipedal rat model, in order to inhibit the effects of melatonin. We sought to understand whether this method can effectively increase the scoliosis rate of bipedal rat model, and to investigate the role of melatonin in scoliosis.

\section{Methods}

\section{Experimental animals}

This study was approved by the Ethic Committee of Fudan University, and all the procedures were completed in the Experimental Animals Department of Medical College of Fudan University. This study used 60 3-week-old Sprague-Dawley rats (SPF level), which were purchased from the Experimental Animals Department of the Medical College of Fudan University.

\section{Experimental method}

The rats used for the experiment were randomly separated into 3 groups (A, B and C), with 20 included in each group. All the rats were kept in indoor in cages with a room temperature of $22 \pm 2{ }^{\circ} \mathrm{C}$. Natural light or light was available from 8:00 - 20:00, and the lights were off during the remaining hours. Groups A and B were fed in raised cages by a qualified person, with adequate food and water. The height at which food and water were placed was modified based on the growth rate of the rats. After 1 week of adaptive growth, groups A and $\mathrm{B}$ underwent osteotomy of the bilateral proximal humerus and proximal tailbone following anesthetization (10\% chloral hydrate $3 \mathrm{ml} / \mathrm{kg}$ intraperitoneal injection) $[4,13]$. Rats in Group A and Group C received an intraperitoneal injection of the melatonin antagonist (Luzindole) (sigma, USA) at $0.2 \mathrm{mg} / \mathrm{kg}$ [15].

Weight was measured before the surgery, 1 month after the surgery, 3 months after the surgery, and 6 months after the surgery. X-rays $(41 \mathrm{kv}, 2.80 \mathrm{mAs})$ of the full spine were taken to calculate the Cobb's angle of the spine $\left(>10^{\circ}\right.$ was considered scoliosis) at the same time. At the end of the experiment $(6$ months after the surgery), all rats were euthanized by overdose anesthetics, and thrombocytes were centrifugalized from venous blood to determine the calmodulin level by ELISA.

\section{Statistical methods}

SPSS 12.0 was used for statistical analysis. The Kolmogorov-Smirnov test was used to determine whether the data of each group conformed to a Gaussian distribution. At each time point, the Kruskal-Wallis test was used to compare Cobb's angle, weight, and thrombocyte calmodulin level between groups. The scoliosis rates of different groups were compared using the chi-square test. A $p$ value $<0.05$ was considered statistically significant.

\section{Results}

One rat in Group A died as a result of anesthetization, 1 rat in Group B died of infection, and all other rats lived to the end of experiment in healthy condition (data in Table 1). Before the surgery, scoliosis or other deformity was not observed in any of the rats (Cobb's angle: $2.7 \pm 2.1^{\circ}$ ).

There were no significant differences in scoliosis rate or severity of scoliosis between Group A and Group B $(P>0.05)$ (Fig. 1$)$ at 1 month after surgery. At 3 months after surgery, the scoliosis rate in Group A was significantly higher than that in Group B $(P<0.05)$, but the difference in the severity of scoliosis was non-significant 
Table 1 Cobb's angle of each group at different time

\begin{tabular}{lllll}
\hline & Before surgery $\left(^{\circ}\right)$ & 1 month after surgery $\left(^{\circ}\right)$ & 3 months after surgery $\left(^{\circ}\right)$ & 6 months after surgery $\left(^{\circ}\right)$ \\
\hline Group A & $2.8 \pm 2.2(20 / 20)$ & $7.0 \pm 5.4(19 / 20)$ & $13.0 \pm 9.3(19 / 20)$ & $17.2 \pm 11.6(19 / 20)$ \\
Number of scoliosis & $/$ & 3 & 12 & 14 \\
Group B & $2.6 \pm 2.0(20 / 20)$ & $5.0 \pm 4.3(19 / 20)$ & $7.8 \pm 8.0(19 / 20)$ & $9.1 \pm 9.2(19 / 20)$ \\
Number of scoliosis & & 1 & 3 & 6 \\
Group C & $2.6 \pm 2.2(20 / 20)$ & $3.2 \pm 2.6(20 / 20)$ & $3.6 \pm 2.7(20 / 20)$ & $3.8 \pm 2.9(20 / 20)$ \\
Number of scoliosis & $/$ & $/$ & $/$ & $/$
\end{tabular}

$(a / b): b$ is the number of rats included in the group; $a$ is the number of rats included in the measurement

"/": No scoliosis

(Fig. 1). At 6 months after surgery, the scoliosis rate in Group A was significantly higher than that in Group B $(P<0.05)$, and the Cobb's angle of Group A was significantly greater than that of Group B $(P<$ 0.05) (Fig. 1; Fig. 2). During the whole experiment, rats in Group $\mathrm{C}$ did not show any scoliosis, and the Cobb's angle of Group C was significantly smaller than those of Group A and Group B at any time point $(P<0.05)$ (Table 1$)$.

The differences of the calmodulin level in thrombocyte among three groups were non-significant (Group A: $140.0 \pm 9.6$; Group B: $137.4 \pm 8.6$; Group C: $138.4 \pm$
7.8).As such no significant difference was found in data of weight among three groups (Table 2) $(P>0.05)$.

\section{Discussion}

This study proves that the application of the melatonin antagonist Luzindole can improve the success rate of the bipedal rat scoliosis model.

Compared to the non-injection group, most rats in the Luzindole injection group developed scoliosis by 3 months after surgery. This confirmed that the decrease in melatonin level during early growth facilitated scoliosis or the tendency to develop scoliosis. With weight

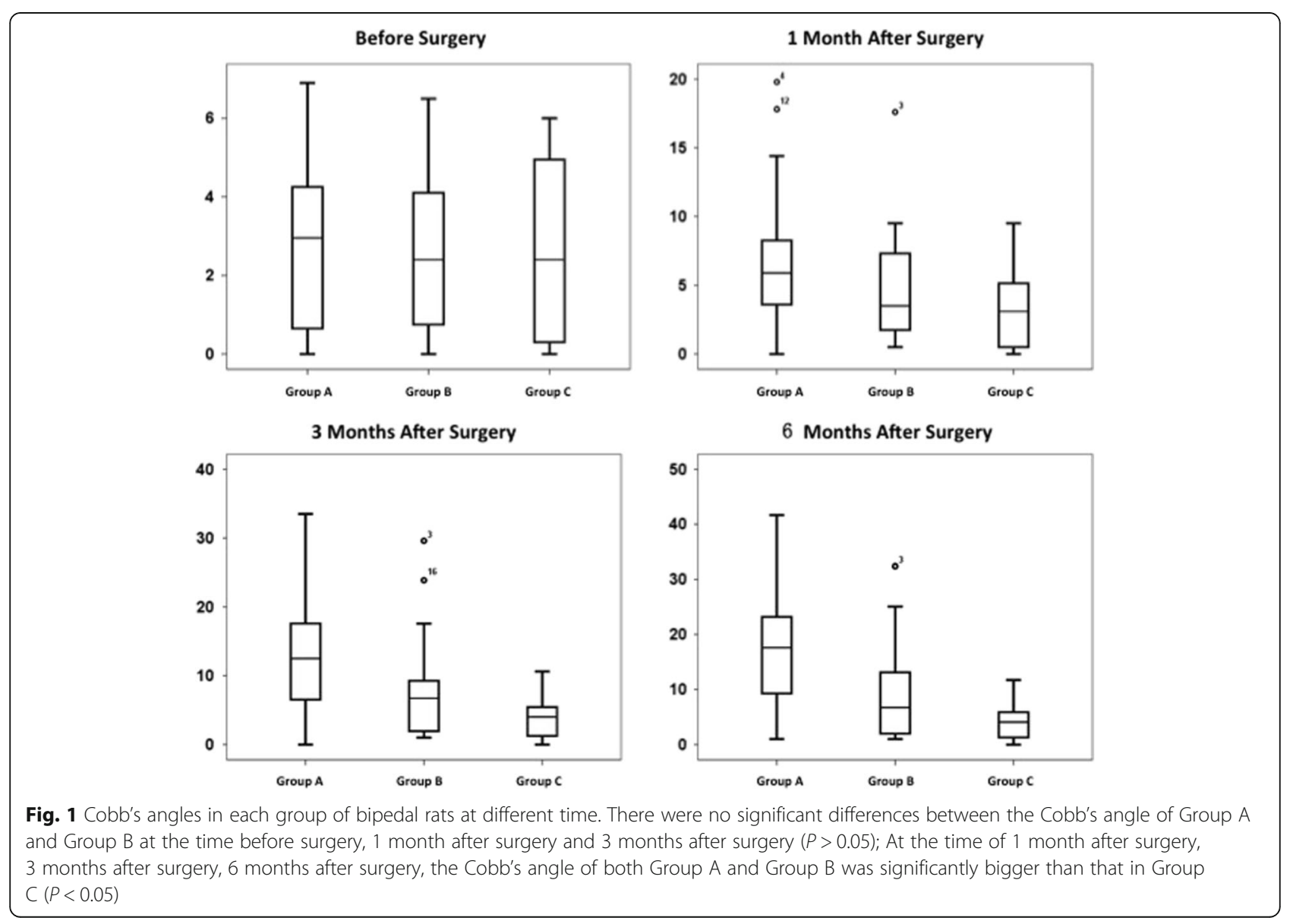




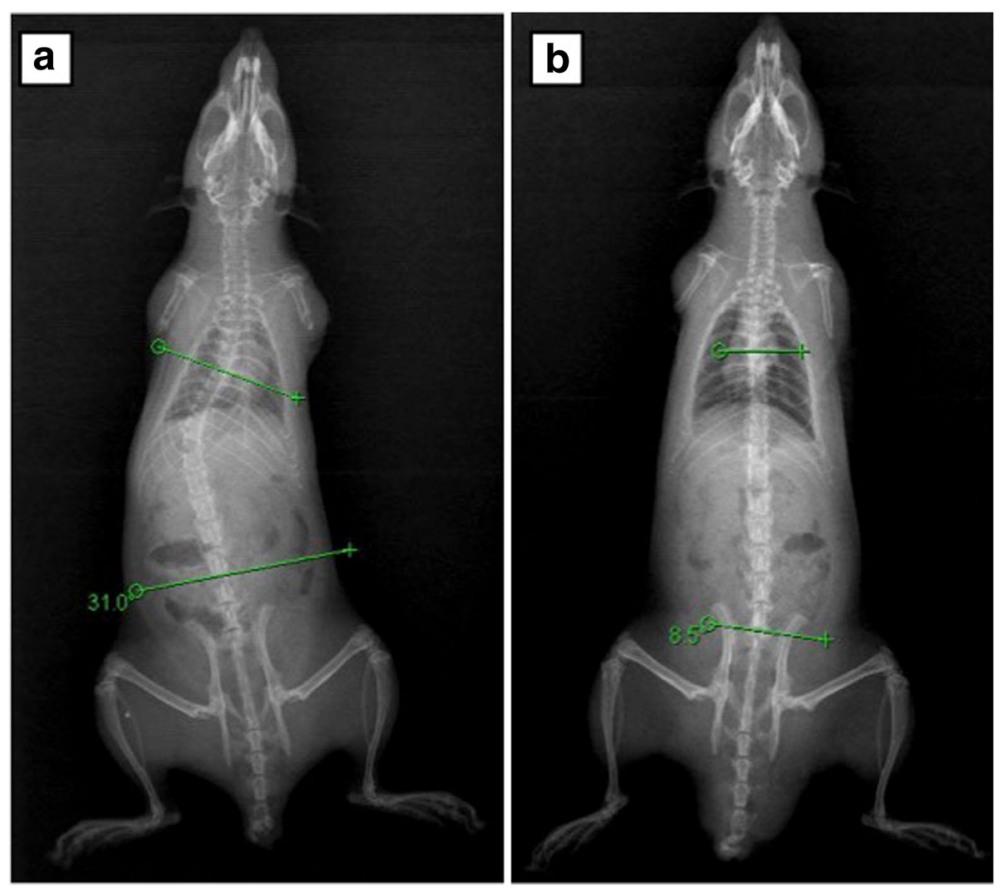

Fig. 2 X-ray films of bipedal rats in Group A and Group B 6 months after surgery. The scoliosis was more severe in the Luzindole-injected bipedal rats

gain, scoliosis may be aggravated because of the biomechanical factors of imbalance. Additionally, no additional rats in Group A developed scoliosis after 3 months after surgery and the increase in Cobb's angle was much greater than that in Group B.

However, in this study, we also showed that Luzindole injection alone could not induce scoliosis in rats, indicating that melatonin deficiency or inhibition is not sufficient to induce scoliosis. O'Kelly's study showed that the fore feet rats did not develop scoliosis after pineal body excision [5], which indicates that the role of melatonin deficiency in the pathogenesis of scoliosis is mostly synergistic; Wu's study has confirmed this finding [16].

In this study, the scoliosis rate in the Luzindole injection group was approximately $70 \%$, and the remaining rats in the group did not show scoliosis at the end of the experiment. This may be attributable to a partial block of the melatonin receptor. Melatonin has two receptor subtypes in human body, MT1B and MT1A. Luzindole only blocks the high-affinity receptor, MT1B, while leaving the lowaffinity receptor, MT1A, uninhibited [17]. This may impact the scoliosis rate. As such, there are two peaks in the melatonin level during the course of a day (12:00 and 18:00-20:00) $[15,16]$, and we only inhibited the second peak, while the first peak was not inhibited, which may have led to the low scoliosis rate. In addition, according to Benitez-King's report, melatonin can act as an antagonist of calmodulin, and calmodulin can also play an important role in the pathogenesis of scoliosis [18]. Akel's study proved that the application of a calmodulin antagonist can protect mice from scoliosis [19]. Therefore, after using Luzindole to block the melatonin receptor, there would be spare melatonin in the body, which may act as an antagonist of calmodulin to prevent scoliosis [20]. However, in this study, the calmodulin level did not show significant difference between the groups, which indicates that Luzindole was not overused. However, the most suitable dose remains to be investigated.

The small sample size is an additional limitation to the injection dose issue. More accurate results will require larger a sample size and a more refined group division. Meanwhile, the scoliosis rate may improve if Luzindole

Table 2 Weight of each group at different time

\begin{tabular}{lllll}
\hline & Before surgery & 1 month after surgery & 3 months after surgery & 6 months after surgery \\
\hline Group A & $100.7 \pm 6.0(20 / 20)$ & $180.7 \pm 24.4(19 / 20)$ & $290.0 \pm 30.3(19 / 20)$ & $360.1 \pm 26.5(19 / 20)$ \\
Group B & $97.5 \pm 4.8(20 / 20)$ & $190.8 \pm 26.6(19 / 20)$ & $283.5 \pm 30.8(19 / 20)$ & $349.1 \pm 24.7(19 / 20)$ \\
Group C & $97.5 \pm 5.4(20 / 20)$ & $183.1 \pm 27.1(20 / 20)$ & $289.6 \pm 26.9(20 / 20)$ & $355.5 \pm 22.9(20 / 20)$ \\
\hline
\end{tabular}

$(\mathrm{a} / \mathrm{b})$ : $\mathrm{b}$ is the number of rats included in the group;a is the number of rats included in the measurement 
were injected at both daily melatonin peaks. This will need further study to determine.

\section{Conclusion}

The application of the melatonin antagonist of Luzindole can improve the success rate of the bipedal rat scoliosis model. Meanwhile, this study indicates that a decreased melatonin level is not the primary cause of scoliosis, but that it may increase the likelihood and severity of scoliosis.

\section{Abbreviations}

AIS: Adolescent idiopathic scoliosis; RCT: Randomized controlled trial

\section{Acknowledgements}

Not applicable.

\section{Funding}

This research is sponsored by Science and Technology Commission of Shanghai Municipality (Project no.14140903800).

\section{Availability of data and material}

The datasets used and/or analysed during the current study available from the corresponding author on reasonable request.

\section{Authors' contributions}

SY and XM conceived and designed the study. XX, WZ and XJ performed the experiments. CZ, JJ and FL analyzed the data. SY and CZ wrote the manuscript. XM, JJ and FL reviewed and edited the manuscript. SY and CZ are co-first authors. All authors have read and approved the final manuscript.

\section{Competing interests}

The authors declare that they have no competing interests.

\section{Consent for publication}

Not applicable.

Ethics approval and consent to participate

The Ethic Committee of Fudan University has approved this study (No.TVII0036-2014036)

\section{Publisher's Note}

Springer Nature remains neutral with regard to jurisdictional claims in published maps and institutional affiliations.

\section{Author details}

${ }^{1}$ Department of Orthopedics, Huashan Hospital, Fudan University, No.12, Middle Wulumuqi Road, Shanghai 200040, China. 'Department of Orthopedics, The Fifth People's Hospital, Fudan University, No.128, Ruili Road, Shanghai 200240, China.

Received: 23 January 2017 Accepted: 22 March 2017

Published online: 04 April 2017

\section{References}

1. Goldberg CJ, Moore DP, Fogarty EE, et al. Adolescent Idiopathic Scoliosis [J]. Spine. 2001;26(1):42-7.

2. Kouwenhoven JW, Castelein RM. The pathogenesis of adolescent idiopathic scoliosis: review of the literature [J]. Spine. 2008;33(26):2898-908.

3. Liu L, Zhu Y, Han X, et al. The creation of scoliosis by scapula-tocontralateral ilium tethering procedure in bipedal rats: a kyphoscoliosis model.[J]. Spine. 2011;36(17):1340-9.

4. Goff CW, Landmesser W. Bipedal rats and mice; laboratory animals for orthopaedic research [J]. J Bone Joint Surg. 1957;39-A(3):616-22.

5. O'Kelly C, Wang X, Raso J, et al. The production of scoliosis after pinealectomy in young chickens, rats, and hamsters [J]. Spine. 1999;24(1):35-43.
6. Barrios C, et al. Paraspinal muscle pathology in experimental scoliosis [J]. Arch Orthop Trauma Surg. 1989:108(6):342-5.

7. Oyama J, Murai I, Kanazawa K, et al. Bipedal ambulation induces experimental scoliosis in C57BL/6 J mice with reduced plasma and pineal melatonin levels [J]. J Pineal Res. 2006;40(3):219-24.

8. Herrera-Marschitz M, Utsumi H, Ungerstedt U. Scoliosis in rats with experimentally-induced hemiparkinsonism: dependence upon striatal dopamine denervation [J]. J Neurol Neurosurg Psychiatry. 1990;53(1):39-43.

9. Thillard MJ. Vertebral column deformities following epiphysectomy in the chick [J]. Comptes Rendus Hebdomadaires Des Séances De Lacadémie Des Sciences. 1959:248(8):1238-40.

10. Bagnall KM, Raso VJ, Hill DL, et al. Melatonin levels in idiopathic scoliosis. Diurnal and nocturnal serum melatonin levels in girls with adolescent idiopathic scoliosis [J]. Spine. 1996;21(21):1974-8.

11. Brodner W, Krepler P, Nicolakis M, et al. Melatonin and adolescent idiopathic scoliosis [J]. Bone Joint J. 2000;82(3):399-403.

12. Fjelldal PG, Grotmol S, Kryvi $\mathrm{H}$, et al. Pinealectomy induces malformation of the spine and reduces the mechanical strength of the vertebrae in Atlantic salmon, Salmo salar [J]. J Pineal Res. 2004;36(2):132-9.

13. Machida M, Saito M, Dubousset J, et al. Pathological mechanism of idiopathic scoliosis: experimental scoliosis in pinealectomized rats [J]. Eur Spine J. 2005:14(9):843-8.

14. Moreau A, Wang DS, Forget $S$, et al. Melatonin signaling dysfunction in adolescent idiopathic scoliosis [J]. Spine. 2004:29(16):1772-81.

15. Ma XS, Lu FZ, Wu JZ, et al. Establishment of the scoliosis model in bipedal rats [J]. Chinese J Spine Spinal Cord. 2009:19(10):774-7.

16. Wu JZ, Wu WH, He L, et al. Effect of Melatonin and Calmodulin in an Idiopathic Scoliosis Model [J]. 2016.

17. Dubocovich ML. Luzindole (N-0774): a novel melatonin receptor antagonist [J]. J Pharmacol Exp Ther. 1988;246(3):902-10.

18. Benítez-King G, Huerto-Delgadillo L, Antón-Tay F. Melatonin modifies calmodulin cell levels in MDCK and N1E-115 cell lines and inhibits phosphodiesterase activity in vitro [J]. Brain Res. 1991;557(1-2):289-92.

19. Akel I, Demirkıran G, Alanay A, et al. The effect of calmodulin antagonists on scoliosis: bipedal C57BL/6 mice model [J]. Eur Spine J. 2009:18(4):499-505.

20. Akel I, Kocak O, Bozkurt G, et al. The effect of calmodulin antagonists on experimental scoliosis: a pinealectomized chicken model [J]. Spine. 2009; 34(6):533-8.
Submit your next manuscript to BioMed Central and we will help you at every step:

- We accept pre-submission inquiries

- Our selector tool helps you to find the most relevant journal

- We provide round the clock customer support

- Convenient online submission

- Thorough peer review

- Inclusion in PubMed and all major indexing services

- Maximum visibility for your research

Submit your manuscript at www.biomedcentral.com/submit 